REVIEW ARTICLE

\title{
Impact of salinization and pollution of groundwater on the adaptation of mosquito vectors in the Jaffna peninsula, Sri Lanka
}

\author{
S.N. Surendran ${ }^{1, *}$, M. Senthilnanthanan ${ }^{2}$, T.T.P. Jayadas ${ }^{1}$, S.H.P.P. Karunaratne ${ }^{3}$ and R. Ramasamy ${ }^{1}$ \\ ${ }^{1}$ Centre for Research in Entomology, Department of Zoology, Faculty of Science, University of Jaffna, Jaffna, Sri Lanka. \\ ${ }^{2}$ Department of Chemistry, Faculty of Science, University of Jaffna, Jaffna, Sri Lanka. \\ ${ }^{3}$ Department of Zoology, Faculty of Science, University of Peradeniya, Peradeniya, Sri Lanka.
}

Received: 26/05/2020 ; Accepted: 03/06/2020

\begin{abstract}
Mosquito-borne diseases are a major health concern in many tropical and sub-tropical countries. In the absence of specific treatment for many mosquito-borne diseases, vector control in the form of eliminating preimaginal development sites and insecticide application has an important role in controlling these diseases. Anthropogenic environmental changes have become important driving forces causing the adaptation of many major mosquito vectors to such changes. Anthropogenic activities are major contributors to global warming that is causing arise in sea levels. Sea level rise along with over exploitation of groundwater results in sea water intrusion to fresh water aquifers causing fresh water salinization in coastal zones. Human activities, including the extensive use of fertilizers and agrochemicals, also cause groundwater pollution. Mosquito vectors that normally lay eggs and undergo preimaginal development in fresh water are now seen to be adapting to develop in brackish and polluted water habitats. This article reviews recent findings that show the adaptation of mosquito vectors of human diseases to lay eggs and undergo preimaginal development in groundwater that is undergoing rapid salinization and pollution in the Jaffna peninsula.
\end{abstract}

Keywords: anthropogenic environmental changes, groundwater pollution, Jaffna peninsula, mosquito adaptations, mosquito range expansion, mosquito vector-borne diseases, salinization of groundwater.

\section{INTRODUCTION}

Mosquito-borne diseases are the largest contributor to human vector-borne disease burden with more than $80 \%$ of the world population at risk (Franklinos et al., 2019). Mosquito vectors transmit many parasitic (e.g. malaria, filariasis) and arboviral (e.g. dengue, chikungunya,yellow fever and Zika fever) diseases that cause significant mortality and morbidity in many countries. It has been estimated that in 2018 there were approximately 228 million malaria cases and 405, 000 deaths worldwide, and of these, the Southeast Asia had an estimated 8 million cases and nearly 12,000 deaths (WHO, 2019). Malaria is caused by protozoan parasites of the genus Plasmodium, predominately by Plasmodium vivax and P. falciparum, and is transmitted by several species of Anopheles mosquitoes (Sinka et al., 2012). Lymphatic filariasis is caused by the nematode parasites Wuchereria bancrofti, Brugia malayi and Brugia timori and is a disease that is present in 49 countries with an estimated 893 million people at risk (WHO, 2020a). Different species of mosquitoes transmit lymphatic filariasis. Mosquito species belong to genus Culex are the widespread vectors while Anopheles and Aedes mosquitoes transmit the disease in rural areas and some Pacific islands respectively (WHO, 2020a). Dengue is an arboviral disease with an estimated 100-400 million infections worldwide. A fifteen-fold increase has occurred in the number of dengue cases worldwide during the last two decades (WHO, 2020b). There were 146, 914 confirmed cases of chikungunya worldwide in 2016 (WHO, 2020c). Zika fever outbreaks have been recorded from 87 counties with a peak in transmission during 2015-2016 in Africa, the Americas, Southeast Asia and Western Pacific and there has been over 2 million reported cases in the Americas alone since 2007 (WHO, 2020d). Yellow fever is prevalent across 47 countries in Africa and the Americas with approximately 170, 000 cases and 60, 000 deaths (WHO, 2020e). Mosquito species Aedes aegypti and Aedes albopictus are considered as the primary and secondary mosquito vectors respectively that transmit dengue, chikungunya, yellow fever and Zika in tropical and subtropical countries. The mosquito Aedes aegypti originated in the forests of tropical Africa but its subsequent adaptation to blood-feed on humans and oviposit and undergo preimaginal development in water collections near human habitations has facilitated its global spread (Crawford et al., 2017). Aedes aegypti has long been regarded to develop only in fresh water collections near human habitations (Barraud, 1934). Aedes albopictus is also considered to be an invasive sylvatic species that has also adapted more recently to develop in freshwater habitats in the urban and semi-urban environment in many countries, including Sri Lanka (WHO, 2012; Ramasamy et al., 2011). Aedes albopictus has recently expanded its range to temperate countries by developing a diapausing egg stage that has enabled it to survive winters (reviewed in Ramasamy and Surendran, 2012).

The mosquito-borne diseases malaria, dengue and filariasis have been historically prevalent in Sri Lanka. In 2016, WHO declared Sri Lanka free of malaria and 
filariasis. Anopheles culicifacies has been the major vector of malaria in Sri Lanka along with other number of secondary vectors that include An. subpictus, An. varuna and An. annularis (reviewed in Surendran and Ramasamy, 2010). Culex quinquefasciatus was the main vector of filariasis in Sri Lanka (Anti-Filariasis Campaign, 2017). Aedes aegypti and Ae. albopictus, the proven vectors of dengue, are present in the country (WHO, 2017). Although malaria and filariasis have been eradicated, the potential vectors of all major mosquito vector-borne diseases continue to be prevalent throughout the island.

Jaffna peninsula lies in northern Sri Lanka and has been endemic for malaria and dengue. Systematic studies on vector mosquitoes in the peninsula were not performed before and during the civil war of 1983-2009. However, entomological studies done after 2009 have shown that mosquito vectors of peninsula are undergoing rapid adaptation to anthropogenically induced environmental changes and these pose an immense challenge to mosquito vector control. Similar adaptive changes in mosquito vectors are now also being observed in other parts of the world.

\section{Mosquito-borne diseases in the Jaffna peninsula and Sri Lanka}

Malaria was endemic in Sri Lanka, including the Jaffna peninsula, for centuries but the country succeeded in formally eliminating the disease in 2013 (Wijesundere and Ramasamy, 2017). However, the prevalence of potent anopheline vectors throughout the island poses the risk of malaria being reintroduced by infected travelers (Wijesundere and Ramasamy, 2017) and by wind-borne, trans-national dispersion of malaria-infected anophelines across the Palk Strait (Surendran et al., 2020). Dengue and its serious manifestation as dengue hemorrhagic fever remain a major public health concern in the country. In year 2019 there were 105,049 dengue cases reported in Sri Lanka (Epidemiology Unit, 2020). Filariasis and Japanese encephalitis are the two other important mosquito-borne diseases in Sri Lanka. Although filariasis has been eliminated from Sri Lanka, both these diseases are transmitted by Culex mosquitoes that continue to be highly prevalent throughout the island (Anti-Filariasis Campaign, 2012). An outbreak of chikungunya occurred during 2006/2007 period in Sri Lanka (Razmy, 2014).

The Jaffna peninsula had been endemic for malaria for many years. Two of the most recent epidemics of malaria occurred in the Jaffna peninsula during 1994-95 and 1997-98. However, only two cases were reported in 2006 and since then no cases has been reported from the Jaffna district (Kannathasan et al., 2008). There have been no reported cases of Japanese encephalitis and filariasis in Jaffna peninsula in recent times, while dengue has become a major public health problem in Jaffna peninsula in recent years with the number of cases increasing from 894 in 2012 to 2468 in 2016 (Surendran et al., 2018a). A total of 6075, 4058 and 8261 dengue cases have been since reported for the years 2017, 2018 and 2019 respectively for the Jaffna district (Epidemiology Unit, Sri Lanka, 2020). An epidemic of chikungunya was reported to have affected thousands of people in the peninsula during 2006-2007 (Surendran et al., 2007).

\section{Mosquito vectors adapting to anthropogenic environmental changes}

Anthropophilic mosquito vectors have, therefore, evolved over a long-time period to take advantage of changes in the environment caused by human population increase and expansion, and societal features such as agriculture and urbanization, and these have markedly impacted the transmission and prevalence of mosquito-borne diseases (Vora, 2008; Ramasamy and Surendran, 2016). Many of the dominant mosquito vectors are anthropophagic (WHO, 2015 a,b) and have evolved behavioral traits and ecological features to lay eggs and undergo preimaginal development in freshwater habitats in close proximity to human dwellings. For example, Ae. aegypti can develop in water collections within houses (Juliano and Lounibos, 2005) and malaria vectors in freshwater pools and water storage tanks near houses and other buildings (Barraud, 1934; Thomas et al., 2016; Surendran et al., 2020).

The availability of water habitats where mosquitoes undergo preimaginal development determines numbers of adult mosquitos produced and therefore their density and human-biting rate. Mosquito productivity is strongly influenced by various biotic (e.g. predation, competition) and abiotic (e.g. temperature, $\mathrm{pH}$, salinity, dissolved solids, turbidity) factors and the interactions between these factors (Rejmànkovà et al., 2013).

Environmental changes orchestrated by human activities can create new habitats within the natural range of the mosquito vectors. Creation of new habitats can increase vector population and thereby disease transmission. Anthropogenic activities can also eliminate natural preimaginal habitats (e.g. Aedes source reduction in dengue vector control) of mosquito vectors. This can be a driving force for mosquitoes adapting to utilize less optimal unfavorable habitats within their natural range. In such a scenario mosquito vectors undergo physiological and genetic changes to develop in less suitable habitats within their natural range. Such adaptive changes allow mosquito vectors to expand their range to invade other areas and neighboring countries where similar habitats are available (Hufbauer et al., 2012; Ramasamy and Surendran, 2016). This ability has been termed as anthropogenically induced adaptation to invade in mosquitoes (Ramasamy and Surendran, 2016). The process of developing such anthropogenically-induced adaptation to invade in mosquito vectors is illustrated in Figure 1.

Environmental changes due to deforestation and agricultural practices, and expansion create new preimaginal habitats for mosquito development. Deforestation resulting from agriculture expansion creates ecological heterogeneities that provide novel habitats for mosquitoes to adapt and undergo preimaginal development which in turn are capable of increasing disease transmission (Rejmànkovà et al., 2013). High incidence of chikungunya in Kerala, India has been associated with the adaptation of Ae. albopictus developing in latex-collecting containers attached to rubber 


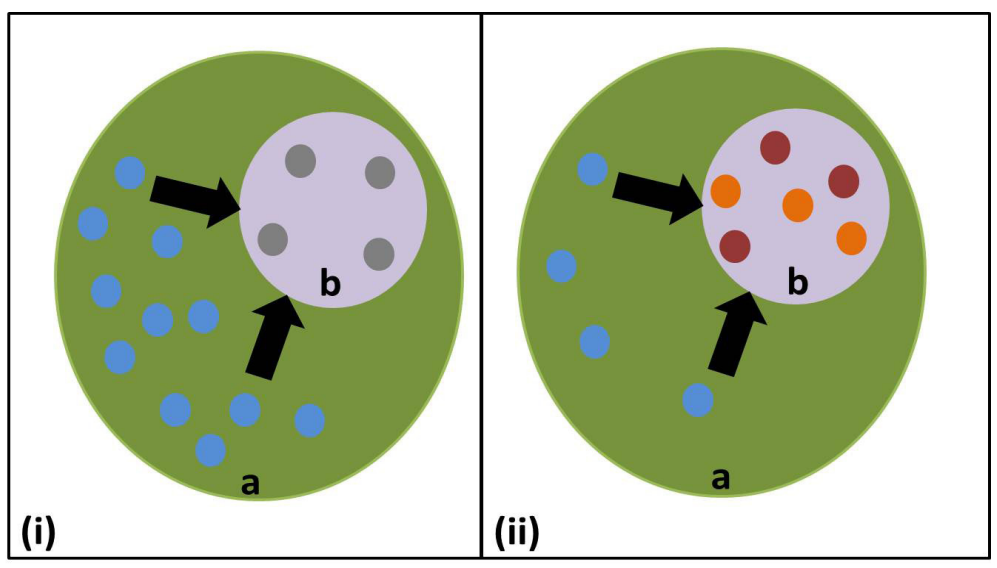

Figure 1: (i). Diagrammatic illustration of mosquito vectors expanding to new habitats within their natural range - (a): Existing natural habitats (blue solid circles) for preimaginal development; (b): Anthropogenic activities create new habitats (ash solid circles) for preimaginal development within the natural range of the mosquitoes. (ii). Diagrammatic illustration of anthropogenic activities eliminating existing habitats in the natural range of mosquito vectors leading to their adaptation to other less desirable habitats within their range - (a) Existing natural habitats (blue solid circles) for preimaginal development; (b) Mosquitoes adapting to other less desirable habitats (brown and orange solid circles) in their natural range.

tree-trunks in rubber plantation (Sumodan, 2012; Sumodan et al., 2015). Deforestation has resulted in increased malaria transmission in parts of Amazon as habitat changes favoured the development of Anopheles darling (Vittor et al., 2009). Ecological segregation of closely related malaria vectors namely An. gambiae s. s and An. coluzzi was attributed to deforestation in Central Africa (Kamdem et al., 2012). Ecological segregation due to adaptation can lead to speciation. Anopheles coluzzi (formally known as the An. gambiae M form) and An.gambiae s. s. (formally designated as the An. gambiae $\mathrm{S}$ from) were shown to have adapted to more polluted urban habitats created after deforestation and less polluted rural habitats respectively in the Cameroons (Kamdem et al., 2012). Agriculture development associated with building infrastructure and irrigation facilities can lead to ecological changes that alter and/or create habitats for mosquito development that can influence disease transmission. A well-studied malaria outbreak along the Demerara river estuary in Guyana in South America was partly attributed to rice cultivation that provided preimaginal habitats for the locally prevalent salinity tolerant and highly exophilic and zoophagic $A n$. aquasalis to become endophilic and anthropophagic (Giglioli et al., 1963). A high prevalence of malaria in the vicinity of newly constructed Mahaweli irrigation canals in north-central Sri Lanka was attributed to a high density of An. annularis developing in the canals that produced high entomological inoculation rates (Ramasamy et al., 1992).

Urbanization alters a natural ecosystem for human settlements. Urban developments that lack the infrastructure facilities to support large human populations are prone to public health challengers (Vora, 2008). Urbanization and human migration have also been attributed to the expansion of the range of vector mosquitoes into new territories. Habitat modification and fragmentation due to urbanization can lead to phenotypic trait selection in different taxa (Alberti, 2015; Alberti et al., 2017). The expansion of the range of Ae. aegypti from African forests and $A e$. albopictus from Asia to many countries in the Americas and Europe is largely attributed to phenotypic trait selection from zoophagicity to anthropophagicity and adaptation to preimaginal development in domestic or peri-domestic environments (Powell et al., 2013; Scot et al., 2000) along with international trade (Benedict et al., 2007; Kraemer et al., 2019). Anopheles stephensi is a major urban vector of malaria in many Asian countries because it has become adapted to develop in cemented wells and cement overhead water storage tanks in the urban environment. The recent range expansion and invasion of An. stephensi to Djibouti in 2013 (Faulde et al., 2014), Ethiopia in 2016 (Carter et al., 2018) and Sri Lanka in 2017 (Dharmasiri et al., 2017) has been attributed to trade, urbanization and associated water storage practices (Surendran et al., 2019a).

It is in this contextual framework of mosquito-vectors of human diseases undergoing adaptation to anthropogenic changes in the environment, that the present article describes the impacts of increasing salinization and pollution of groundwater on mosquito disease vectorsin the Jaffna peninsula.

\section{Global warming, sea level rise and salinization of groundwater in coastal areas}

Global warming, which has been largely attributed to human activity, can affect human health in multiple ways. Global climate change due to global warming has been predicted by modeling studies to increase the global spread of mosquito-borne diseases like malaria and dengue but also reduce their incidence in some presently endemic areas (Franklinos et al., 2019; Ogden, 2017; McMichael et al., 2006; Confalonieri et al., 2007; Hunter, 2003). Various models predict the effects of changing temperature, rainfall and humidity on mosquito development and survival and shortening the extrinsic incubation period of pathogens in mosquitoes (Confalonieri et al., 2007; Githeko et al., 2000). Global warming is predicted to increase average sea levels by 18 to $59 \mathrm{~cm}$ by the end of the 21 st century mainly 
due to the melting of glaciers and thermal expansion of seawater (UNIPCC, 2007). Rising sea levels is expected to increase the extent of saline or brackish water bodies (water with $<0.5 \mathrm{ppt}$ or parts per thousand which is approximately the grams per litre, $0.5-30 \mathrm{ppt}$ and $>30 \mathrm{ppt}$ salt are termed fresh, brackish and saline respectively) in coastal areas such as coastal estuaries, lagoons, marshes and mangroves, and cause the intrusion of sea water into freshwater aquifers (Nicholls et al., 2007; FAO, 2007; Ramasamy and Surendran, 2011; 2012). As a consequence, freshwater bodies such as ponds, lakes and wells in coastal areas will become more brackish and cause potable water scarcity in coastal areas. The expansion of brackish and saline water bodies, mainly in coastal areas, can increase the transmission of mosquito-borne diseases (Ramasamy and Surendran, 2012).

Countries like Sri Lanka with extensive coastlines and high coast to land area ratios are particularly vulnerable to the impact of rising sea levels (Table 1). Coastal areas are highly populated and one in ten persons worldwide lives in coastal areas (McGranahan et al., 2007). Many countries in South and Southeast Asia have large proportion of their populations living in coastal areas that are vulnerable to the consequences of rising sea level. It has been postulated that rising sea levels due to global warming will increase the prevalence of many vector-borne diseases, including mosquito-borne diseases, initially along coasts before spreading inland (Ramasamy and Surendran, 2011; Ramasamy et al., 2015).

Jaffna peninsula has an extensive coastal line with many sea water inlets (Figure 2). It is undergoing rapid groundwater salinization due to over exploitation and sea water intrusion into fresh water aquifer systems. Rise in sea level due to anthropogenically induced global warming is expected to increase sea water intrusion to aquifer systems in the peninsula (Ramasamy and Surendran, 2011). This will extend salinization of groundwater to many parts of the peninsula and increase the availability of preimaginal habitats for mosquito vectors that are adapted to develop in brackish water.

\section{Increasing salinization and pollution in the Jaffna peninsula}

Sri Lanka is an island with a land area of $64,630 \mathrm{~km}^{2}$. It has a $1,340 \mathrm{~km}$ coastline with coastline/land area ratio of $20.7 \mathrm{~km}^{2}$ (Ramasamy et al., 2015). The Jaffna peninsula in northern Sri Lanka (Figure 2) lies in the island's dry zone (Gunaalan et al., 2018). The temperature typically varies from 20.8 to $34.3^{\circ} \mathrm{C}$. Most of the rainfall in the peninsula is derived from the North-East monsoon (October to December) with a more minor and variable contribution to the rainfall from the South-West monsoon (April to July)

Table 1: Coastline in relation to land cover in selected countries in South Asia.

(adapted from Ramasamy et al., 2015)

\begin{tabular}{cccc}
\hline Country & $\begin{array}{c}\text { Land area } \\
\mathbf{K m}^{\mathbf{2}}\end{array}$ & $\begin{array}{c}\text { Coastline } \\
\mathbf{K m}\end{array}$ & $\begin{array}{c}\text { Coastline/Land area ratio } \\
\mathbf{m} / \mathbf{K m}^{\mathbf{2}}\end{array}$ \\
\hline Bangladesh & 130,168 & 580 & 4.5 \\
\hline India & $2,973,193$ & 7,000 & 2 \\
\hline Sri Lanka & 64,630 & 1,340 & 20.7 \\
\hline Malaysia & 328,657 & 4,675 & 14.2 \\
\hline Indonesia & $1,811,569$ & 54,716 & 30.2 \\
\hline Philippines & 298,170 & 36,289 & 121.7 \\
\hline
\end{tabular}

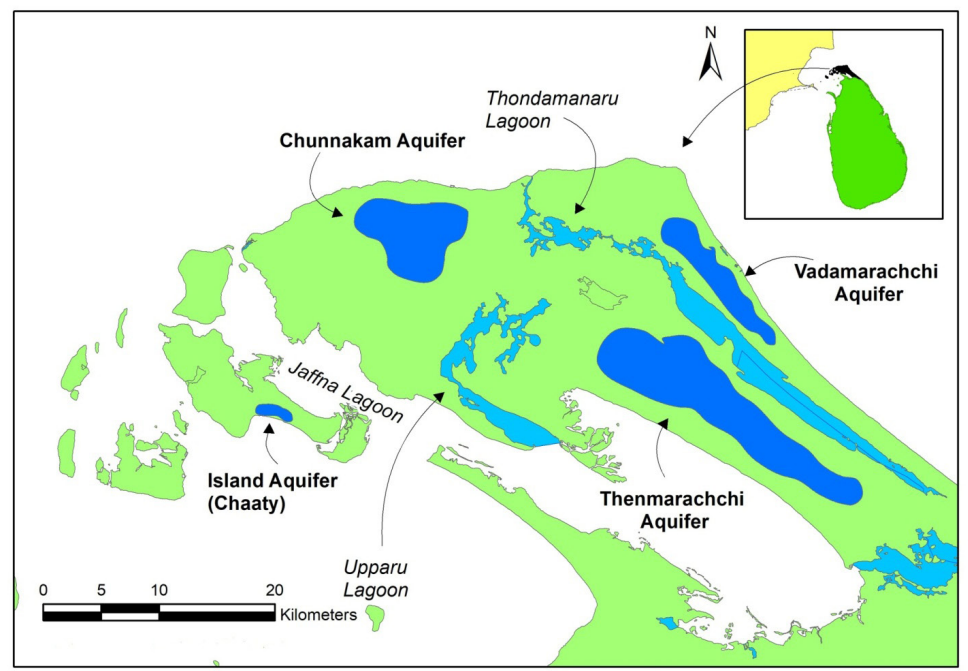

Figure 2: Map of Jaffna peninsula showing lagoons and freshwater aquifer systems. (Source: National Atlas of Sri Lanka) 
yielding an annual average rainfall of 1,121mm (Annual Performance and Accounts Report: Jaffna District, 2018).

The Jaffna peninsula (which together with outlying islands constitutes the bulk of the administrative district of Jaffna) has a total land area of $1025 \mathrm{~km}^{2}$ with average elevation of $5 \mathrm{~m}$ above sea level. The estimated total population in 2018 was 615,493 with the population density of 600.48 persons $/ \mathrm{km}^{2}$. The distance to the coast from any location in the peninsula is $<10 \mathrm{~km}$ and thus the entire peninsula can be considered to be a coastal zone. The population of the Jaffna district increased from 265,600 to 831,800 during the one hundred year period between 1881 and 1981 . There was a sharp decline caused by the civil war from 1983 to 2009, to 541,380 in 2001. The population has now increased to 615,490 in 2018 .

The Jaffna peninsula and adjoining islands have an underlying Miocene limestone formations inland and unconsolidated formations such as lagoonal and estuarine deposits, and coastal and dune sands near the sea (Sirimanne, 1952; Cooray, 1984). The limestone bedrock, which is primarily made up of calcite (Panabokke and Perera, 2005), extends below sea level and serves as an excellent aquifer (Arumugam, 1970; Joshua et al., 2013). There are four main limestone aquifers in the peninsula and the adjacent islands, viz. Chunnakam (Valikamam), Thenmaradchi, Vadamaradchi and Island (Figure 2) (Puvaneswaran, 1985). The fresh groundwater present in these limestone aquifers occurs in the form of a convex lens, which thins out towards the coast, above the seawater (Joshua et al., 2013) as per the Ghyben-Herzberg principle (Carlson, 1963). The thickness of the freshwater lens is about $25 \mathrm{~m}$ (Arumugam, 1970) and the lower part of the lens is transitional where the freshwater becomes increasingly brackish with depth (TDS 1,500 - 4,000 ppm) (Joshua et al., 2013; Kumara et al., 2013). Further, very limited elevation of the water table above sea level (<1 m - $12 \mathrm{~m})$ (Kumara et al., 2013) reduces the depth of transitional zone (seawater - freshwater interface) in these aquifers and makes them shallow. The water table is lowered by groundwater extraction for irrigation and domestic use and the natural and continuous discharge of groundwater to the sea/lagoon along the coastline under the existing hydraulic gradient. The water table reaches its peak during the North-East monsoon rains. About 30 $\%$ of the rainfall is estimated to recharge groundwater in Jaffna peninsula and the rest of the rain water is lost mainly through direct runoff (about 10-15\%) and evaporation (about 40-48 \%) (Navaratnarajah, 1994). The annual water table fluctuation in the unconfined limestone aquifers of Jaffna peninsula has been reported in the past to be 1-2 $\mathrm{m}$ (Arumugam, 1970; Kumara et al., 2013).

In the absence of any freshwater reservoirs of a perennial nature, the entire population of Jaffna peninsula relies on the groundwater stored in these aquifers to meet all its needs, including drinking, domestic, agriculture and other livelihood purposes (Navaratnarajah, 1994; Joshua et al., 2013; Mikunthan et al., 2013). Water from deep artesian wells in the Chunnakam aquifer is used to provide piped water supply to the city of Jaffna. Other areas of the Jaffna peninsula rely on domestic wells within premises for household water needs. However the groundwater is now brackish in many parts of the peninsula including the neighbouring islands due to complex hydrometeoric, hydrogeologic and hydrogeochemical conditions prevailing in these areas, and an expansion of brackish groundwater has been observed in the past few decades (Nandakumar, 1983; Rajasooriyar et al., 2002). This is mainly caused by seawater intrusion due to excessive extraction of groundwater for domestic use and agriculture by the increasing population of the peninsula, as well evaporation losses from the large diameter open dug wells (Nandakumar, 1983; Puvaneswaran, 1985; Navaratnarajah, 1994; Rajasooriyar et al., 2002).

Even though studies related to occurrence, quantity and quality of the groundwater of Jaffna peninsula had been carried out since 1938 with the available facilities and information at that time, systematic hydrological investigations were initiated only in 1965. After four years of continuous monitoring of over 400 representative observation wells, a preliminary report giving estimates of average freshwater storage (above MSL) during wet and dry seasons and the salinity status of groundwater in different regions of the Jaffna peninsula was first published in 1970 (Arumugam, 1970; Panabokke, 2007). Serious groundwater salinization in the shallow limestone and sandy aquifers in many parts of the Jaffna peninsula, especially in the coasts have since been reported (Gunasekaram, 1983; Nagarajah et al., 1988). Excessive extraction of groundwater for irrigation, anthropogenic activities such as high fertilizer inputs, improper sewage systems, landfills, etc. have also contributed to the groundwater salinity in Jaffna peninsula (Puvaneswaran, 1985; Navaratnarajah, 1994; Mikunthan et al., 2013). There has been no systematic monitoring of groundwater salinization the peninsula since the 19832009 civil war but limited observations suggest a severe deterioration of water quality (Rajasooriyar et al., 2002; Pathmaja et al., 2016; Chandrajith et al., 2016).

Groundwater in the coastal area is relatively vulnerable to contamination by seawater intrusion either by fall on the groundwater table near the coasts or increase in sea levels that can enhance the intrusion of seawater into the aquifer. Therefore, the groundwater in coastal areas can readily become brackish (Chandrajith et al., 2013). The chloride concentration in the coastal regions of the major aquifers of Jaffna peninsula reaches up to $2.8 \mathrm{~g} / \mathrm{L}$ and makes those areas vulnerable to high salinity; but chloride concentration is less than $200 \mathrm{mg} / \mathrm{L}$ in the inland areas of these aquifers (Mageswaran et al., 2004). High electrical conductivity along with high chloride concentrations provide evidence for seawater intrusion (Rajasooriyar et al., 2002) and salinity in general in the Jaffna groundwater is inversely proportional to the distance from the sea (Puvaneswaran, 1987). Groundwater salinization via mixing of sea water due to low elevated groundwater table and highly porous geological formations in a neighbouring island (Pungudutivu) of Jaffna peninsula along with dissolution and leaching of evaporative salts has also been reported (Pathmaja et al., 2016).

Generally, groundwater in the limestone aquifers 
possesses high electrical conductivity and high hardness due to dissolution of calcium carbonate from the limestone. As a consequence, high concentration of calcium ions too has been found in the drinking water of Jaffna peninsula (Kumara et al., 2013).

Although initiatives such as constructing earth bunds in coastal areas to prevent seawater intrusion during high tides and building a number of surface water tanks to harvest the excess rainwater that would infiltrate and reduce salinity in the limestone aquifers of Jaffna peninsula have been promoted for decades, a comprehensive longterm solution to the water shortage in the peninsula remains to be evolved.

Groundwater resources are extensively used for domestic as well as agricultural purposes in Jaffna peninsula are now severely polluted due to unsustainable levels of usage of fertilizers, agrochemicals and improper sewage management. There is no piped sewage disposal system in the Jaffna peninsula. Therefore sewage, even in the densely populated Jaffna city is treated in septic tanks within individual domestic and business premises. Household grey water wastes are directed to open drains in Jaffna city (Figure 3). The main drains discharge grey waste water into the Jaffna lagoon. However some of the grey waste water percolates into the groundwater within the peninsula. Additionally, many chemicals used in agriculture also percolate directly into the groundwater. As a result wells used for obtaining drinking water in most areas of the peninsula are heavily polluted. There are more than 100,000 dug wells which are used for agriculture and domestic purposes in Jaffna peninsula (Kraft, 2002). There has been increasing pollution of the groundwater in the peninsula and this has been reported for many decades (Mageswaran and Mahalingam, 1983; Mageswaran, 2003).

A study based on samples collected from Jaffna peninsula revealed that out of 40 wells $38 \%$ were highly contaminated with coliform bacteria and the parameters recorded were not within the drinking water quality standards of WHO. Nearly $80 \%$ of wells were found not suitable for drinking based on the values specified in guidelines for drinking water quality on electrical conductivity (Mahagamage et al., 2019). Another study investigated nitrate-N contamination in wells associated with Chunnakam aquifer (Figure 1) revealed that $28 \%$ of the 44 wells examined exceeded the permissible level of Nitrate-N (Vithanagae et al., 2014). High concentration of Nitrate- $\mathrm{N}$ in the range of 7.1 to $15.3 \mathrm{mg} / \mathrm{L}$ was found in drinking water supply wells in Jaffna (Jeyaruba and Thushyanthi, 2009). The high nitrate levels recorded in the well waters is associated with agriculture practices in which inorganic fertilizers are heavily applied (Mikunthan et al., 2013). Total phosphate level in groundwater of the peninsula varied from 0 to 3 $\mathrm{mg} / \mathrm{L}$, exceeding the permissible level of $2 \mathrm{mg} / \mathrm{L}$ in some locations (Mageswaran, 2003). Rapid development of small industries, increasing agricultural activities together with a population increase that contributes nitrate contamination by domestic pit latrines, is expected to increasingly contaminate groundwater resources in the limestone strata of Jaffna peninsula (Vithanagae et al., 2014).

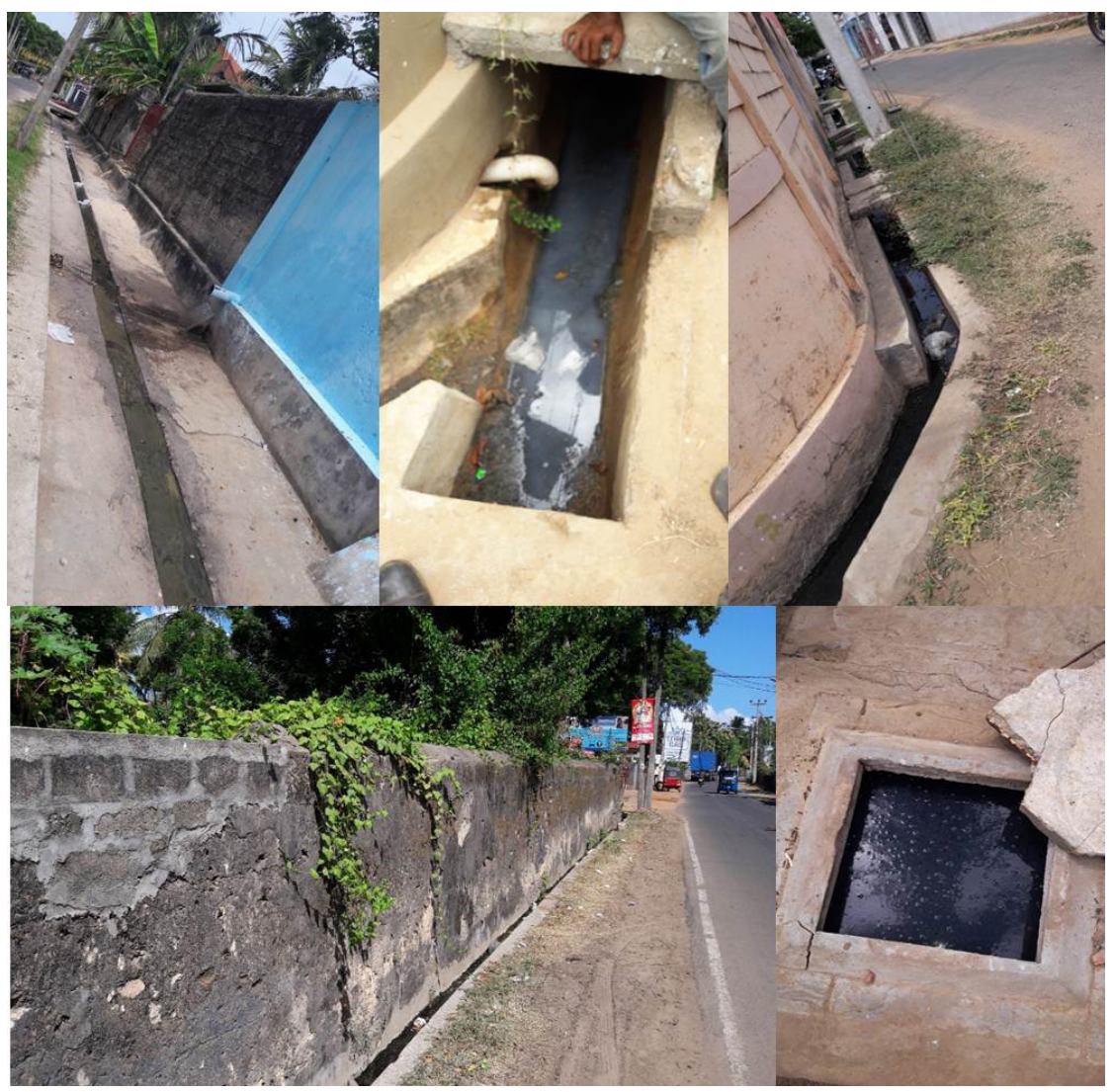

Figure 3: Open surface drain system in Jaffna city that increases ground water pollution and provide sites for preimaginal development of mosquito vectors. 
Impact of increasing salinization of coastal groundwater on mosquito vectors of human diseases

There are number of mosquito vectors of human diseases among the approximately $5 \%$ of mosquito species that naturally develop in brackish water and saline waters around the world. Examples of prominent salinity tolerant vectors are shown in Table 2. It is expected that the expansion of brackish water bodies will increase the densities of salinity-tolerant vector mosquitoes that undergo preimaginal development in brackish water and saline waterbodies (Ramasamy and Surendran, 2011; Ramasamy, 2015; Ramasamy et al., 2015; Surendran et al., 2012). Jude et al. (2010) observed the development of An. culicifacies, the major vector of malaria in the Indian subcontinent, in brackish water of up to $4 \mathrm{~g} / \mathrm{L}$ or ppt salt in coastal areas of eastern Sri Lanka. It was subsequently observed that the many other mosquito vectors widely held to develop only in fresh water, are also capable of ovipositing and undergoing preimaginal development to adults in brackish water in coastal areas of the Jaffna peninsula and adjoining islands (Jude et al., 2012) (Table 3; Figure 2). The prominent freshwater vector species Ae. aegypti and Ae. albopictus have since our initial observation in Jaffna peninsula been reported to develop in coastal brackish water habitats in Brunei (Idris et al., 2013), the USA (Yee et al., 2014), Brazil (Arduino et al., 2015) and Mexico (Galaviz-Paradaet al., 2019).

Laboratory investigations showed that the development of Ae. aegypti in brackish water has both inheritable and reversible characteristics (Ramasamy et al., 2014). Aedes aegypti collected from brackish water habitats in the field and maintained in brackish water of $10 \mathrm{~g} / \mathrm{L}$ salt tended to prefer brackish water to fresh water for oviposition and had greater $\mathrm{LC}_{50}$ for tolerating salinity in undergoing preimaginal development to adulthood than fresh water Ae. aegypti collected from and maintained in fresh water (Ramasamy et al., 2014). Further studies showed that brackish water Ae. aegypti developed larger anal papillae, organs that play a role in osmoregulation, than fresh water Ae. aegypti (Surendran et al., 2018b). These findings suggest that there are genetic differences exist between brackish water and fresh water Ae. aegypti in the Jaffna peninsula. Although interbreeding between brackish and fresh water Ae. aegypti from Sri Lanka was observed (Ramasamy et al., 2014), the findings demonstrate a potential for speciation in Ae. aegypti in the long term if fresh water and brackish water developing populations become reproductively isolated through efforts to eliminate their freshwater preimaginal habitats or geographically isolated in the Jaffna peninsula. Laboratory studies showed that the effect of salinity has a negative impact on the toxicity of Bacillus thuringiensis (Bt) to Ae. aegypti larvae (Jude et al., 2012). Since Ae. aegypti is adapted to salinity, it is expected that $B t$ will be less effective in controlling the brackish water population (Jude et al., 2012). Also it was found that both the brackish and fresh water developing female Ae. aegypti and Ae. albopictus were susceptible to DENV infection and the infected mosquitoes were able to vertically (transovarially) transmit DENV to their eggs and subsequent progeny (Surendran et al., 2018a). Vertical transmission maintains DENV among field Aedes vectors without a need to take a blood meal from dengue patients, a situation that is neither possible nor observed in anopheline vectors of malaria (Surendran et al., 2018a).

It has been shown that brackish water-derived $A e$. aegypti remain relatively susceptible to malathion (an organophosphate insecticide) and permethrin (a pyrethroid). These and related insecticides of the two classes may

Table 2: Common salinity-tolerant mosquito vectors of human disease.

(adapted from Ramasamy and Surendran, 2011 and 2012)

\begin{tabular}{lll}
\hline \multicolumn{1}{c}{ Species } & \multicolumn{1}{c}{ Distribution } & \multicolumn{1}{c}{ Transmitted pathogens } \\
Aedes dorsalis & Temperate Eurasia, N America & $\begin{array}{l}\text { West Nile virus and Western equine } \\
\text { encephalitis virus }\end{array}$ \\
\hline Ae. (Ochlerotatus) taeniorhynchus & N \& S America & Eastern equine encephalitis virus \\
\hline Ae. togoi & North Pacific rim & $\begin{array}{l}\text { Japanese encephalitis virus and filarial } \\
\text { parasites }\end{array}$ \\
\hline Ae. (Ochlerotatus) vigilax & Australasia, SE Asia & $\begin{array}{l}\text { Filarial parasites, Ross River virus, } \\
\text { Barmah forest virus }\end{array}$ \\
\hline Anopheles atroparvus & Coast of W Europe & Malaria parasites \\
\hline An. farauti and An. annulipes & Australasia & Malaria parasites \\
\hline An. melas and An. merus & Africa & Malaria parasites \\
\hline An. multicolor & N Africa, Middle East & Malaria parasites \\
\hline An. sacharovi & Russia, S Europe & Malaria parasites \\
\hline An. subpictus & Asia & Malaria parasites \\
\hline An. sundaicus & S Asia, SE Asia, China & Malaria parasites \\
\hline Culex sitiens & Indian ocean rim countries & $\begin{array}{l}\text { Japanese encephalitis virus and Ross } \\
\text { River virus }\end{array}$ \\
\hline Cx. tritaeniorhynchus & Russia, Middle East, Africa, India & Japanese encephalitis virus \\
\hline
\end{tabular}


Table 3: Freshwater mosquito vectors of human diseases that have adapted to brackish water habitats in the Jaffna peninsula and islands in the Palk Strait.

\begin{tabular}{lllll}
\hline \multicolumn{1}{c}{ Species } & $\begin{array}{l}\text { Transmitted disease/ } \\
\text { medical significance }\end{array}$ & \multicolumn{1}{c}{ Location } & $\begin{array}{c}\text { Maximum } \\
\text { salinity } \\
\text { tolerance } \\
\text { (g/L) }\end{array}$ & \\
\hline Aedes aegypti & Dengue, chikungunya & Jaffna city & 15 & Reference \\
\hline Aedes albopictus & Dengue, chikungunya & Jaffna city & 14 & Ramasamy et al., 2011 \\
\hline Anopheles culicifacies & Malaria & Delft, Jaffna city & 4 & Jude et al., 2012; Surendran et al., 2020 \\
\hline Anopheles subpictus & Malaria & Jaffna city & 3.4 & Surendran et al., 2020 \\
\hline Anopheles stephensi & Malaria & Jaffna city & 3.5 & Surendran et al., 2020 \\
\hline Anopheles varuna & Malaria & Jaffna city, Delft & 4 & Jude et al., 2012; \\
\hline Anopheles barbirostris & Malaria & Delft, Sarasali & 6 & Surendran et al., 2020 \\
\hline \multirow{2}{*}{ Lutzia fuscanus } & Not a vector but feeds & & & Jude et al., 2012 \\
\hline & $\begin{array}{l}\text { on larvae of mosquito } \\
\text { vectors }\end{array}$ & Nainativu & 10 & Jude et al., 2012 \\
\hline
\end{tabular}

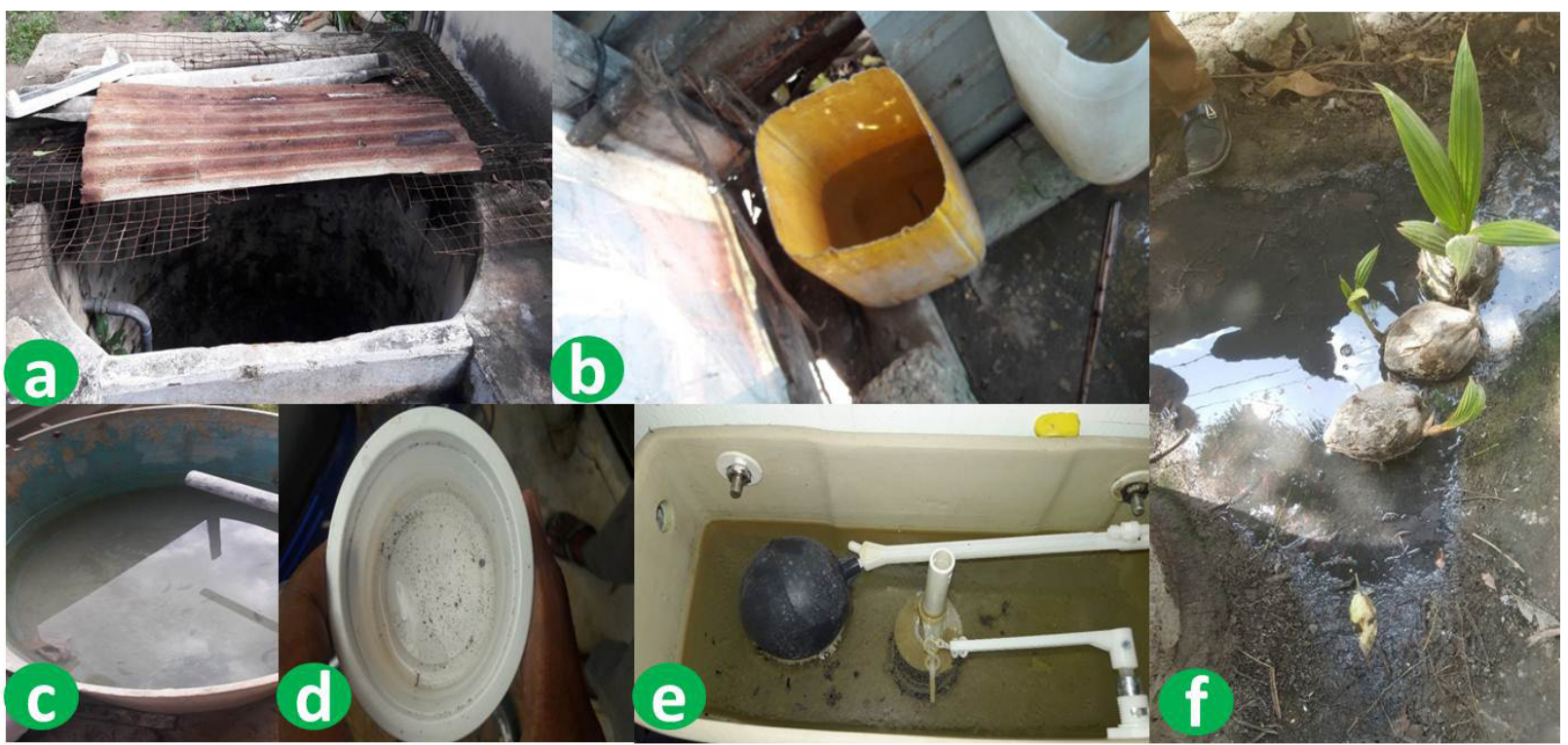

Figure 4: Brackish water habitats for preimaginal development of mosquito vectors in the Jaffna peninsula.- a. Domestic well with 5 g/L (ppt) salt brackish water, b. Plastic bucket with $2 \mathrm{~g} / \mathrm{L}$ (ppt) salt brackish water, c. Water tank with $2 \mathrm{~g} / \mathrm{L}$ (ppt) salt brackish water, d. Plastic container with $3 \mathrm{~g} / \mathrm{L}$ (ppt salt brackish water, e. A puddle in a domestic area with $2 \mathrm{~g} / \mathrm{L}$ (ppt) salt brackish water and f. Open water flush with $3 \mathrm{~g} / \mathrm{L}$ (ppt) salt brackish water.

therefore be useful for controlling brackish water-derived coastal populations of Ae. aegypti. The reported differential susceptibility to malathion also suggests that there are genetic differences between brackish water-derived $A e$. aegypti and fresh water -derived Ae. aegypti in the Jaffna peninsula (Ramasamy et al., 2014).

Anopheles culicifacies is the major vector of malaria in Sri Lanka (Carter, 1930; Amerasingheet al., 1991; Surendran et al., 2000). Studies reveal that An. culicifacies undergoes preimaginal development in brackish water in Jaffna peninsula, in Jaffna city and Delft (Table 3). Anopheles stephensi, the dominant urban malaria vector in India, is also found in other parts of Asia and Middle East. This invasive species was first detected in Mannar island in the Northern Province of Sri Lanka in 2017 and subsequently in domestic wells and water storage tanks in Jaffna city in 2018, with a genotype consistent with an origin in Tamil Nadu (Surendran et al., 2018c; Surendran et al., 2019a). The preimaginal stages of An.stephensi were found to tolerate brackish water of up to $3.5 \mathrm{~g} / \mathrm{L}$ or ppt salt in Jaffna city (Surendran et al., 2020). Anopheles subpictus species A, a secondary vector of malaria in Sri Lanka, was observed developing in $3.4 \mathrm{~g} / \mathrm{L}$ or ppt saltbrackish water habitats in Jaffna city. The normally fresh water developing malaria vector An. varuna was also found capable of developing in brackish water of up to $1.4 \mathrm{~g} / \mathrm{L}$ or ppt salt in Jaffna city (Table 3; Figure 4) (Surendran et al., 2020).

These observations in the Jaffna peninsula are 
examples of the process where elimination of the natural habitats of vector mosquitoes by human activity has led the vectors to adapt to less desirable new habitats within their natural range. It has been hypothesized that the Aedes vectors developing in brackish water habitats is a globally widespread phenomenon favoured wholly or partly by the exclusive focus of dengue control measures on fresh water habitats (Ramasamy et al., 2011, 2015).

\section{Impact of increasing groundwater pollution on mosquito vectors of human diseases}

Anthropogenic activities can have great impact on ecosystems and this process is greatly exacerbated by a rapidly increasing population. Industrialization and rapid urbanization often necessitate rapid adaptation to changing complex environments. Heavy discharge of industrial waste, household wastes, unhygienic sewage system and widespread use of xenobiotics in agriculture and public health increases selective pressures on pathogens and their vectors (Hendry et al., 2017).

The preimaginal development of Ae. aegypti in highly polluted domestic septic tanks have been reported in Puerto Rico and Nigeria (Burke et al., 2010). A recent study showed that Aedes mosquitoes developing in human urine contaminated aquatic environments can acquire and transmit Zika virus (Du et al., 2019). Recently, Ae. aegypti in developing in polluted water in open surface drains were reported in Jaffna peninsula (Surendran et al., 2019b) and Colombo (Chandrasiri et al., 2020). Anophles culicifacies, the primary malaria vector in Sri Lank, has long been regarded to develop only in clear, sunlit and unpolluted, fresh water collections with high dissolved oxygen content, but its larvae were recently found developing in polluted water in blocked urban drains in eastern Sri Lanka (Gunathilaka et al., 2013). Range expansion and adaptation to atypical habitats have contributed for insecticide selection pressure to vector mosquitoes to become resistant to common insecticides. Resistance in the Anopheles gambiae complex to permethrin, have been associated with oil spills in Nigeria (Djouaka et al., 2007, 2008), and resistance to deltamethrin with the use of agricultural chemicals in Tanzania (Nkya et al., 2014).

Of considerable concern was the observation that $A e$. aegypti adapted to undergo preimaginal development in polluted water in open surface drains in the Jaffna peninsula showed greater resistance in adult stages to the common pyrethroids deltamethrin and permethrin than fresh water Ae. aegypti (Surendran et al., 2019b). Furthermore the resistance to pyrethroids in polluted water Ae. aegypti adults was characterized by elevated levels of two groups of pyrethroid-detoxifying enzymes, viz. glutathione-S-transferases and monoxygenases. Therefore it seems possible that adaptation in preimaginal stages of Ae. aegypti to detoxify pollutants present in drain water can also result in an increased capacity of adults to detoxify pyrethroids (Surendran et al., 2019b). Since the application of pyrethroid insecticides is the mainstay for controlling epidemics of arboviral diseases worldwide, and open drains are common in congested urban areas of tropical arboviral disease-endemic countries, this observation is of great international concern (Surendran et al., 2019b).

A recent study revealed that the fresh water developing malaria vectors in Sri Lanka namely An. culicifacies, An. subpictus, An. varuna and An. stephensi had adapted to develop in polluted water in the Jaffna peninsula (Surendran et al., 2020). The polluted water developing An. subpictus in the Jaffna peninsula was resistant to deltamethrin with a characteristic L1014F (TTA to TTC) knock-down resistance mutation, found in Indian An. subpictus (Singh et al., 2015), in the IIS6 transmembrane segment of the voltage gated sodium channel protein (Surendran et al., 2020).

Therefore, adaptation to polluted water in urban areas has two major detrimental effects on vector control. Firstly, the range and diversity of pre-imaginal habitats of polluted water-resistant vectors increases and this results in greater vector densities. Secondly, adapting to polluted water also causes greater resistance to commonly used insecticides thereby reducing the efficacy of insecticides used to control adult vector populations.

\section{Range expansion of vector mosquito species}

The westward range expansion of An. stephensi in the middle-east was attributed to the favorable conditions created by rapid social development and urbanization (Alahamed et al., 2012).The invasion into horn of Africa was postulated to have been caused by transportation of goods and movement of refugees across the Red Sea (Faulde et al., 2014). A southward range expansion of $A n$. stephensi was observed in India along the west coast from Goa to Kanyakumari in South India in the 1980s. The range expansion was attributed to urbanization and associated water storage practices in India (Sharma and Hamzakoya, 2001).The urban malaria vector further expanded its range across Palk strait to northern Sri Lanka, initially to Mannar island (Dharmasiri et al., 2017) and Jaffna city (Figure 5) (Surendran et al., 2018c).

Anopheles stephensi exists as three biotypes namely An. stephensi mysorensis, An. stephensi intermediate and An. stephensi type. The rural mysorensis and intermediate forms have evolved to adapt to develop in freshwater ponds, stream beds, wells and seepage canals while the urban An. stephensi sensu stricto or type form populations develop mainly in artificial water containers, over ground water storage tanks, domestic wells, underground cement water storage tanks, evaporator coolers, cisterns, barrels, roof gutters, pits in construction sites and ornamental tanks (WHO, 2007; Sharma et al., 1993; Thomas et al., 2016).

The newly invasive An. stephensi in Jaffna peninsula has the intrinsic plasticity to develop in fresh water, brackish water and polluted water habitats. These characteristic were likely to have been developed in urban India and gives An. stephensi the advantage to expand its range to new territories, including North Sri Lankais an example of the proposed anthropgenically-induced adaptation to invade in mosquito vectors (Ramasamy and Surendran 2016). Studies have shown that An. stephensi has euryhaline characteristics and is able to develop in brackish water in Pakistan (Reisenet al., 1981; Roberts, 1996). Environmental 


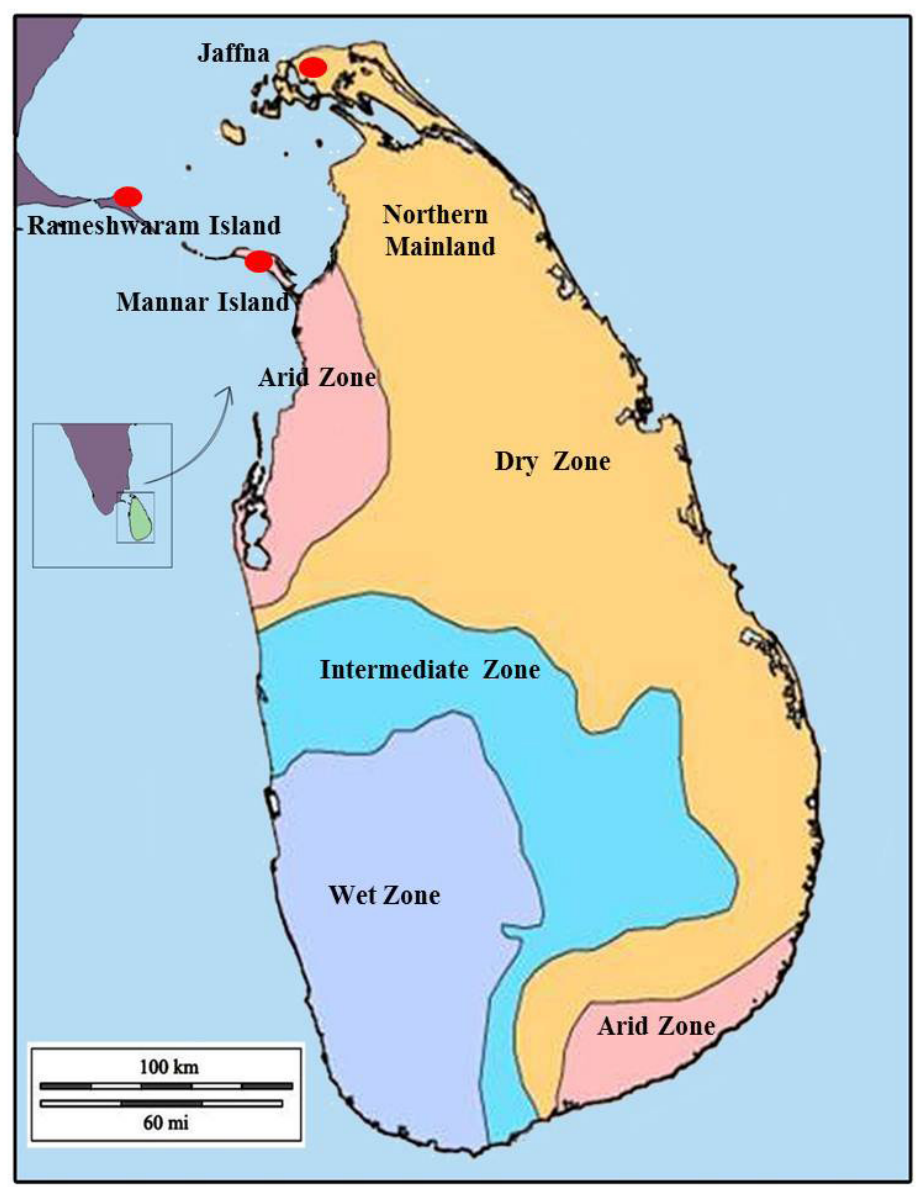

Figure 5: The map of Sri Lanka in the Indian Ocean showing the postulated southward expansion of An. stephensi from Rameshwaram island of South India onto Mannar island and Jaffna city of northern Sri Lanka.

modifications that caused water logging and salinization favored salinity-tolerant An. stephensi (Reisen et al., 1981) becoming the dominant malaria vector in South Punjab, Pakistan (Klinkenberg et al., 2004). The northern Jaffna peninsula limestone geology and salinization of fresh water aquifers provide brackish water habitats for the preimaginal development mosquito vectors as stated above. It is therefore likely that An. stephensi that has evolved to undergo preimaginal development in brackish water, can utilize similar anthropogenic brackish water habitats to further extend its range within the Jaffna peninsula and other coastal areas of Sri Lanka.

The movement of people has been an important factor in the geographic spread of insects to new territories (Palkovacs et al., 2012). There has been relatively free movement across the 64 to $137 \mathrm{~km}$-wide Palk Strait that separates northern Sri Lanka from Tamil Nadu (Figure 5) in the past. It is, therefore, reasonable to assume that $A n$. stephensi arrived in Sri Lanka from Tamil Nadu. It appears likely that eggs and larvae in brackish water collections within small fishing boats was the probable method of arrival of An. stephensi in northern Sri Lanka. However wind-borne dispersion of An. stephensi from Tamil Nadu during the South-West monsoon is also a possibility in view of recent data from the Sahel region of Africa showing that anopheline vectors can be passively dispersed over hundreds of kilometers by winds (reviewed in Surendran et al., 2020)

The establishment of An. stephensi population in Jaffna peninsula has been facilitated by environmental and biological factors that include availability of urban domestic wells and cement water storage tanks as habitats to which it was already adapted in India, the adaptation to undergo preimaginal development in brackish water man-made habitats in coastal areas which may also have been previously acquired in coastal areas of Tamil $\mathrm{Nadu}$, and resistance to pyrethroid, organophosphate and organochlorine insecticides which may also have been previously developed in Tamil Nadu (Surendran et al., 2019b). The above factors are examples of mosquitoes adapting to changing environment and the anthropogenically-induced adaptation to invade in mosquito vectors of human disease (Ramasamy and Surendran, 2016)

\section{Implications for increased disease transmission}

More than half of the world's population lives within 60 $\mathrm{km}$ of a shoreline. Population density in coastal areas is expected to increase from 87 persons per $\mathrm{km}^{2}$ in the year 2000 to 134 persons per $\mathrm{km}^{2}$ in 2050 (UNEP, 2007). This will place more people at risk of exposure to many mosquito-borne diseases by the increasing mosquito vector population in coastal areas.

Rising sea levels resulting from human induced global 
warming will increase sea water intrusion and expand the extent of brackish water bodies in coastal areas that in turn can facilitate salinity adaptation in fresh water vectors and increase the numbers of existing salinity-tolerant vectors (Ramasamy and Surendran, 2011.

The intrinsic plasticity allows mosquitoes to develop in atypical habitats. Genetic changes associated with resistance to insecticides contribute to adaptation to salinity in $A e$. aegypti (Ramasamy et al., 2014) and oil pollution in An. gambiae (Djouakaet al., 2008). This has implications for the worldwide prevalence of vector mosquitoes adapting to develop in atypical habitats and therefore the control of mosquito-borne diseases in many countries.

Mosquito vectors adapted to the new habitats therefore have the potential to extend their range to similar habitats in other areas. Brackish water-adapted Ae. aegypti and Ae. albopictus in Sri Lanka can expand their range to similar coastal brackish water habitats in Sri Lanka and neighbouring countries in the Indian Ocean. Similarly, pollutant-adapted An. gambiae from Lagos have been predicted to be able to spread to develop in polluted water habitats in adjacent territories (Costantiniet al., 2009). Adaptation-associated physiological changes in mosquito vectors can influence the infectivity of pathogens to mosquitoes and thereby influences vectorial capacity (Ramasamy and Surendran, 2016). Further research on mosquito vector ecology and pathogen-vector interaction in the context of vectorial capacity is therefore needed to more effectively control mosquito-borne human diseases in the future.

Greater attention is needed on vector prevalence and monitoring of disease incidence in coastal areas. Counter measures should be introduced to prevent further range expansion of mosquito species developing in brackish water and polluted water habitats. Current vector control measures targeting fresh water habits should be extended to brackish and polluted water habitats with community participation and awareness on mosquito vectors developing habitats.

There is a need for more research at local, national and international levels into impact of sea level rise, salinization and pollution on mosquito vectors population in coastal regions. The inherent physiological mechanisms associated with adaptation to develop in brackish water and polluted water needs to be further investigated.

\section{CONCLUSIONS}

Recent findings suggest that the rapid salinization and pollution of groundwater in the Jaffna peninsula and very likely elsewhere in Sri Lanka is leading to the adaptation of fresh water mosquito vectors of malaria and arboviral vectors to brackish water and polluted water with physiological changes that reduce the effectiveness of present vector control methods. There is presently a dearth of studies on the distribution, insecticide resistance, abundance and adaptations of major Culex species that are potential vectors of human diseases in other parts of the country. Furthermore, salinization and pollution of water have direct health impacts on people. Appropriate monitoring and mitigating measures to address these problems are urgently needed in the Jaffna peninsula and other coastal areas of Sri Lanka. A solution to stop and perhaps reverse groundwater salinization in the Jaffna peninsula proposed nearly a century ago was to construct tidal barriers to convert Thondamanaru lagoon (Figure 2) into a freshwater, rain fed reservoir. A sewer system and treatment plant for the city of Jaffna and adjacent suburbs can greatly help to reduce the present levels of groundwater contamination. It was proposed in 2012 that the Jaffna peninsula may constitute a model coastal zone for examining the impacts of global warming, sea level rise and salinization on mosquito-borne diseases (Ramasamy and Surendran, 2012). The recent findings, summarized here, further supports the view that the Jaffna peninsula serves as a global paradigm for the effects of multiple anthropogenic changes on mosquito vectors of human disease in resource-limited tropical countries.

\section{ACKNOWLEDGMENT}

Financial assistance from the National Science Foundation of Sri Lanka (RPHS/2016/D02) is acknowledged.

\section{STATEMENT OF CONFLICT OF INTEREST}

The authors declare that they have no competing interests.

\section{REFERENCES}

Alahamed, A.M. (2012). Mosquito fauna (Diptera: Culicidae) of the Eastern Region of Saudi Arabia and their seasonal abundance. Journal of King Saud University-Science 24:55 - 62.

Alberti, M. (2015).Eco-evolutionary dynamics in an urbanizing planet.Trends in Ecology and Evolution 30: 114-126

Albertia, M., Correab, C., Marzluffc, J.M. et al. (2017). Global urban signatures of phenotypic change in animal and plant populations. Proceedings of the National Academy of Sciences of the United States of America 114 (34): 8951 - 8956.

Anti Filariasis Campaign, Sri Lanka. (2017). Available from: http://www.filariasiscampaign.health.gov.l k/ subpgs/hom_lymphatic.html (Accessed on 28 July 2017).

Anti-Filariasis Campaign, Sri Lanka. (2012). http://203.94.76.60/departmnt/dgfilaria.ht (Accessed on 4 May, 2012).

Amerasinghe, F.P., Amerasinghe, P.H., Peiris, J.S.M. and Wirtz, R.A. (1991). Anopheline ecology and malaria infection during the irrigation development of an area of the Mahaweli Project Sri Lanka. American Journal of Tropical Medicine and Hygiene 45, 226-235.

Arduino, M.B., Mucci, L.F., Serpa, L.L.N. and Rodrigues, M.M. (2015). Effect of salinity on the behaviour of Aedes aegypti populations from the coast and plateau of south-eastern Brazil. Journal of Vector Borne Diseases 52(1): 79 - 87

Arumugam, S. (1970). Development of groundwater and its exploitation in the Jaffna Peninsula. Transactions of the Institute of Engineers Ceylon 1: 31-62. 
Barraud, P.J. (1934). Diptera Vol. 5 Family Culicidae. Tribes Megarhinini and Culicini (Fauna of British India, including Ceylon and Burma). Taylor \& Francis, London.

Benedict, M.Q., Levine, R.S., Hawley, W.A., and Lounibos, L.P. (2007). Spread of the tiger: Global risk of invasion by the mosquito Aedes albopictus. Vector Borne Zoonotic Diseases 7(1): 76 - 85.

Burke, R., Barrer, R., Lewis, M., Kluchinsky, T. and Claborn, D. (2010). Septic tanks as larval habitats for the mosquitoes Aedes aegypti and Culex quinquefasciatus in Playa-Playita, Puerto Rico. Medical and Veterinary Entomology 24: 117-123.

Carlson, C.W. (1963). An early American statement of Boden Ghyben-Herzberg principle of static freshwater-salt-water balance. American Journal of Science 261: 88 - 91 .

Carter, H.F. (1930). Further observations on the transmission of malaria by anopheline mosquitoes in Ceylon. Ceylon Journal of Science 2: 159-176.

Carter, T.E., Yared, S., Gebresilassie, A., Bonnell, V., Damodaran, L., Lopez, K., Ibrahim, M., Mohammed, S. and Janies, D. (2018). First detection of Anopheles stephensi Liston, 1901 (Diptera: culicidae) in Ethiopia using molecular and morphological approaches. Acta Tropica 188: 180-186.

Chandrajith, R., Chaturangani, D., Abeykoon, S., Barth, O.A.C., Geldern, R.V., Edirisinghe, E.A.N. V. and Dissanayake, C.B. (2013). Quantification of groundwater - seawater interaction in a coastal sandy aquifer system: a study from Panama, Sri Lanka. Environmental Earth Science 72(3): 867-877.

Chandrajith, R., Diyabalanage, S.,Premathilake, K.M., Hanke, C., Geldern, R. and Barth, J.A.C. (2016). Controls of evaporative irrigation return flows in comparison to seawater intrusion in coastal karstic aquifers in northern Sri Lanka: evidence from solutes and stable isotopes. Science of the Total Environment 548; 421-428.

Chandrasiri, P., Fernando, H. and De Silva, B. (2020). Pre-imaginal development of Aedes aegypti in drains containing polluted water in urban cities in Sri Lanka. International Journal of Tropical Insect Science 40: 467 - 471.

Confalonieri, U., Menne, B., Akhtar, R., Ebi ,K. L., Hauengue, M., Kovats, R. S., Revich, B. and Woodward, A. (2007). Human health. Climate Change 2007: Impacts, Adaptation and Vulnerability. Contribution of Working Group II to the Fourth Assessment Report of the Intergovernmental Panel on Climate Change. Cambridge University Press, Cambridge, pp. 391-431.

Costantini, C., Ayala, D., Guelbeogo, W.M., Pombi, M., Some, C.Y., Bassole, I.H. et al. (2009). Living at the edge: Biogeographic patterns of habitat segregation conform to speciation by niche expansion in Anopheles gambiae. BMC Ecology 9: 16.

Cooray, P.G. (1984). An introduction to the Geology of Sri Lanka (Ceylon).National Museums Sri Lanka Publication 2: 126-269.

Crawford, J.E, Alves, J.M., Palmer, W.J., Day, J.P, Sylla, M., Ramasamy, R., Surendran, S.N., Black IV, W.C.,
Pain, A. and Jiggins, F.M. (2017). Population genomics reveals that an anthropophilic population of Aedes aegypti mosquitoes in West Africa recently gave rise to American and Asian populations of this major disease vector. BMC Biology 15: 16.

Dharmasiri, A.G., Perera, A.Y., Harishchandra, J., Herath, H., Aravindan, K., Jayasooriya, H.T.R., Ranawaka, G.R. and Hewavitharane, M. (2017). First record of Anopheles stephensi in Sri Lanka: a potential challenge for prevention of malaria reintroduction. Malaria Journal 16:326.

Djouaka, R.F., Bakare, A.A., Bankole, H.S., Doannio, J.M., Coulibaly, O.N., Kossou, H., Tamo, M., Basene, H. I., Popoola, O. and Akogbeto, M. C. (2007). Does the spillage of petroleum products in Anopheles breeding sites have an impact on the pyrethroid resistance? Malaria Journal 6: 159

Djouaka, R.F., Bakare, A.A., Coulibaly, O.N., Akogbeto, M. C., Ranson, H., Hemingway, J. and Strode, C. (2008). Expression of the cytochrome P450s, CYP6P3 and CYP6M2 are significantly elevated in multiple pyrethroid resistant populations of Anopheles gambiae s.s. from Southern Benin and Nigeria. BMC Genomics 9: 538.

Du, S., Liu, Y., Liu, J., Zhao, J., Champagne, C., Tong, L., Zhang, R., Zhang, F., Qin, C., Liang, G., Liu, O., Shi, P., Cazelles, B., Wang, P., Tian, H. and Cheng, G. (2019). Aedes mosquitoes acquire and transmit Zika virus by breeding in contaminated aquatic environments. Nature Communications 10: 1324.

Epidemiology Unit, Sri Lanka.(2020). Dengue Trends. http://www.epid.gov.lk/web/index.php?option=com casesanddeaths\&Itemid $=448 \&$ lang $=\mathrm{en} \#$ (Accessed on 16 May, 2020).

FAO. (2007). Seawater intrusion in coastal aquifers Guidelines for study, monitoring and control. Food and Agricultural Organisation, Rome.

Faulde, M.K., Rueda, L.M. and Khaireh, B.A. (2014). First record of the Asian malaria vector Anopheles stephensi and its possible role in the resurgence of malaria in Djibouti, Horn of Africa. Acta Tropica 139:39-43.

Franklinos, L.H.V., Jones, K.E., Redding, D.W. and Abubakar, I. (2019). The effect of global change on mosquito-borne disease. The Lancet Infectious Diseases 19(9): E302-E312

Galavíz-Parada, J.D., Vega-Villasante, F., Marquetti, M.C., Guerrero-Galván, S., Chong-Carrillo, O., Navarrete Heredia, J.L. and Cupul-Magaña, F.G. (2019). Effect of temperature and salinity on the eclosion and survival of Aedesaegypti (L) (Diptera: Culicidae) from Western Mexico. Revista Cubana de Medicina Tropical, 71(2): $1-15$.

Giglioli, G. (1963). Ecological change as a factor in renewed malaria transmission in an eradicated area. A localized outbreak of An. aquasalis-transmitted malaria on the Demerara River estuary, British Guiana, in the fifteenth year of An. darlingi and malaria eradication. Bulletin of World Health Organization 29: 131 - 45.

Githeko, A.K., Lindsay, S.W., Confalonieri, U.E. and Patz, J.A. (2000). Climate change and vector-borne diseases: a regional analysis. Bulletin of World Health 
Organization, 78: 1136-1147.

Gunesekaram, T. (1983).Ground water contamination and case studies in Jaffna Peninsula, Sri Lanka. Global Engineering Technology Services, Jaffna.

Gunaalan, K., Ranagalage, M., Gunarathna, M.H.J.P., Kumari, M.K.N., Vithanage, M., Srivaratharasan, T., Saravanan, S. and Warnasuriya, T.W.S. (2018). Application of geospatial techniques for groundwater quality and availability assessment: A case study in Jaffna Peninsula, Sri Lanka, ISPRS International Journal of Geo-Information 7: 20.

Gunathilaka, N., Fernando, T., Hapugoda, M., Wickremasinghe, R., Wijeyerathne, P. and Abeyewickreme, W. (2013). Anopheles culicifacies breeding in polluted water bodies in Trincomalee District of Sri Lanka. Malaria Journal 12: 285.

Hendry, A., Gotanda, K. and Svensson, E. (2017). Human influences on evolution, and the ecological and societal consequences. Philosophical Transactions of the Royal Society B: Biological Sciences 372: 1712.

Hufbauer, R.A., Facon, B., Ravingé, V., Turgeon, J., Foucaud, J., Lee, C.E. et al. (2012). Anthropogenically induced adaptation to invade (AIAI): contemporary adaptation to human-altered habitats within the native range can promote invasion. Evolutionary Applications 5(1): 89-101.

Hunter, P.R. (2003). Climate change and waterborne and vector-borne disease. Journal of Applied Microbiology 94: $37 \mathrm{~S}-46 \mathrm{~S}$.

Idris, F.H., Usman, A., Surendran, S.N. and Ramasamy, R. (2013).Detection of Aedes albopictus preimaginal stages in brackish water habitats in Brunei Darussalam. Journal of Vector Ecology 38: 197 - 199.

Jeyaruba, T. and Thushyanthi, M. (2009). The effect of agriculture on quality of groundwater: A case study. Middle East Journal of Scientific Research 4(2):110 114.

Joshua, W.D., Thushyanthy, M. and Nanthagoban, N. (2013). Seasonal variation of water table and groundwater quality of the karst aquifer of the Jaffna peninsula-Sri Lanka, Journal of the National Science Foundation of Sri Lanka 41: 3 - 12.

Jude, P.J., Dharshini, S., Vinobaba, M., Surendran, S.N. and Ramasamy, R. (2010). Anopheles culicifacies breeding in brackish waters in Sri Lanka and implications for malaria control. Malaria Journal 9:106.

Jude, P.J., Tharmasegaram, T., Sivasubramaniyam, G., Senthilnanthanan, M., Kannathasan, S., Raveendran, S., Ramasamy, R. and Surendran, S. (2012). Salinitytolerant larvae of mosquito vectors in the tropical coast of Jaffna, Sri Lanka and the effect of salinity on the toxicity of Bacillus thuringiensis to Aedes aegypti larvae. Parasites and Vectors 5: 269.

Juliano, S.A. and Lounibos, L.P. (2005). Ecology of invasive mosquitoes: Effects on resident species and on human health. Ecology Letters 8(5): 558 - 74.

Kannathasan, S., Antonyrajan, A., Srikrishnaraj, K.A., Karunaratne, S.H.P.P., Karunaweera, N.D. and Surendran, S.N. (2008). Studies on prevalence of anopheline species and community perception of malaria in Jaffna district, Sri Lanka. Journal of Vector
Borne Diseases 45 (3): 231-239.

Kamdem, C., Fossog, B.T., Simard, F., Etouna, J., Ndo, C., Kengne, P., et al.(2012). Anthropogenic habitat disturbance and ecological divergence between incipient species of the malaria mosquito Anopheles gambiae. PLoS One 7(6): e39453.

Klinkenberg, E., Konradsen, F., Herrel, N., Mukhtar, M., van der Hoek, W. and Amerasinghe, F.P. (2004). Malaria vectors in the changing environment of the southern Punjab, Pakistan. Transaction of Royal Society for Tropical Medicine and Hygiene 98: 442 - 9.

Kraemer, M.U.G., Reiner, R.C., Brady, O.J. et al. (2019). Past and future spread of the arbovirus vectors Aedes aegypti and Aedes albopictus. Nature Microbiology 4: $854-863$.

Kraft, H. (2002). Study on water supply, rain water harvesting, waste water and solid waste management in Jaffna municipal council. Jaffna Rehabilitation Project (JRP). January, 2002. Sri Lanka. pp 13-33.

Kumara, I.G.C.I., Rathnnnayaka, S.S.K., Mayadunne, M. M.C.M. and Rajapakse, R.R.G.R. (2013).Assessment of ground water quality in Jaffna Peninsula. Journal of Geological Society of Sri Lanka 15: 137-146.

Mahagamage, M.G.Y.L, Manage, P.S. and Manage, P.M. (2019). Water quality and microbial contamination status of groundwater in Jaffna Peninsula, Sri Lanka. Journal of Water and Land Development 40 : 3 - 12.

Mageswaran, R. and Mahalingam, R. (1983). Nitrate nitrogen content of well water and soil from selected areas in the Jaffna Peninsula. Journal of National Science Council, Sri Lanka 11(1): 269-275.

Mageswaran, R. (2003). Quality of groundwater in the Jaffna Peninsula. International workshop on environmental management in north- east Sri Lanka. 1st- 4th December, 2003. Thirunelvely, Jaffna, Sri Lanka.pp 75-81.

Mageswaran, R., Senthilnanthanan, M., Srikaran, R. and Abiman P. (2004). Quality of ground water in selected areas of northern part of Sri Lanka. Proceedings of Sri Lanka Association for the Advancement of Science 60: 225.

McGranahan, G, Balk, D. and Anderson, B. (2007). The rising tide: assessing the risks of climate change and human settlements in low elevation coastal zones. Environment and Urbananization 19:17

McMichael, A.J., Woodruff, R.E. and Hales, S. (2006). Climate change and human health: present and future risks. Lancet 367: 859-869.

Mikunthan, T., Vithanage, M., Pathmarajah, S., Arasalingam, S., Ariyaratne, R. and Manthrithilake, H. (2013).Hydrogeochemical characterization of Jaffna's aquifer systems in Sri Lanka. Colombo, Sri Lanka: International Water Management Institute (IWMI). pp. 1-69.

Nagarajah, S., Emerson, B.N., Abeykoon, V. and Yogalingam, S. (1988). Water quality of some wells in Jaffna and Kilinochchi with special reference to nitrate pollution. Tropical Agriculturist 144: 61 - 74.

Nanadakumar, V. (1983). Natural environment and ground water in the Jaffna Peninsula, Sri Lanka, Climatological Notes Tsukub 33: 155 - 164. 
Navaratnarajah.V. (1994).Affordable water supply and sanitation Water problems in the Jaffna Peninsula.20 $0^{\text {th }}$ WEDC Conference Colombo, Sri Lanka.

Nicholls, R.J., Wong, P.P., Burkett, V.R., Codignotto, J.O., Hay, J.E., McLean, R.F., Ragoonaden, S. and Woodroffe, C.D. (2007). Coastal systems and lowlying areas. Climate Change : Impacts, Adaptation and Vulnerability. Contribution of Working Group II to the Fourth Assessment Report of the Intergovernmental Panel on Climate Change.Edited by: Parry ML, Canziani OF, Palutikof JP, van der Linden PJ, Hanson CE. 2007, Cambridge: Cambridge University Press, 315-356.

Nkya, T.E., Akhouayri, I., Poupardin, R., Batengana, B., Mosh,a F., Magesa, S. et al. (2014). Insecticide resistance mechanisms associated with different environments in the malaria vector Anopheles gambiae: a case study in Tanzania. Malaria Journal. 13:28.

Ogden, N.H. (2017). Climate change and vectorborne diseases of public health significance. FEMS Microbiology Letters 364: fnx 186.

Palkovacs, E.P., Kinnison, M.T., Correa, C., Dalton, C.M. and Hendry, A.P. (2012). Fates beyond traits: ecological consequences of human-induced trait change. Evolutional Applications 5:183 - 91

Panabokke, C.R. and Perera, A.P.U.R.L. (2005). Groundwater Resources of Sri Lanka. Water Resources Board, Colombo, Sri Lanka.

Panabokke, C.R. (2007). Groundwater conditions in Sri Lanka: a geomorphic perspective. National Science Foundation of Sri Lanka. Journal of the National Science Foundation of Sri Lanka 36 (1): 113 - 114.

Pathmaja, S., Rajasooriyar, L.D., Dharmagunawardhane, H.A., Senthilnanthanan, M. and Mikunthan, T. (2016). Assessment of spatial and temporal behaviour of saline groundwater in a coastal aquifer: A case study from Pungudutivu Island, Jaffna, Sri Lanka. Symposium Proceedings of the Water Professionals'Day, Sri Lanka. pp. 119 - 129.

Powell, J.R. and Tabachnick, W.J. (2013). History of domestication and spread of Aedesaegypti-a review. The Memórias do Instituto Oswaldo Cruz 108 (Suppl. 1), $11-17$

Puvaneswaran, K.M. (1985). Spatial temporal variation and the human dimension of the ground water of Jaffna Peninsula. Beitrage Zur Hydrologie, 5: 827 - 845.

Puvaneswaran, P. (1987). Geomorphology of the Valukkai Aru drainage basin. Sri Lankan Journal of South Asian Studies 1: 43-58.

Rajasooriyar, L.D., Mathavan, V., Dharmagunewardene, H.A. and Nandakumar, V. (2002). Groundwater quality in the Valigamam region of the Jaffna Peninsula, Sri Lanka. In: Hiscock KM, RivettMO, Davison RM (eds) Sustainable groundwater development. Special publications. Geological Society, London, 193:181 197.

Razmy, A. (2014). Clinical features of chikungunya infection in Sri Lanka. Asian Pacific Journal of Tropical Diseases 4(2): 131-134.

Ramasamy, R., De Alwis, R., Wijesundera, A. and Ramasamy, M.S. (1992). Malaria transmission in a new irrigation scheme in Sri Lanka: the emergence of Anopheles annularis as a major vector. American Journal of Tropical Medicine and Hygiene 47:547 - 53.

Ramasamy, R. and Surendran, S.N. (2011). Possible impact of rising sea levels on vector-borne infectious diseases. BMC Infectious Diseases 11: 18.

Ramasamy, R., Surendran, S., Jude, P., Dharshini, S. and Vinobaba, M. (2011).Larval development of Aedes aegypti and Aedes albopictus in peri-urban brackish water and its implications for transmission of arboviral diseases. PLoS Neglected Tropical Diseases 5(11): e1369.

Ramasamy, R. and Surendran, S.N. (2012).Global climate change and its potential impact on disease transmission by salinity-tolerant mosquito vectors in coastal zones. Frontiers in Physiology 3:198.

Ramasamy, R., Jude, P., Veluppillai, T., Eswaramohan, T. and Surendran, S.N. (2014). Biological differences between brackish and fresh water-derived Aedes aegypti from two locations in the Jaffna Peninsula of Sri Lanka and the implications for arboviral disease transmission. PLoS One 9(8): e104977.

Ramasamy, R. (2015). Adaptation of fresh water mosquito vectors to salinity increases arboviral disease transmission risk in the context of anthropogenic environmental changes. In: Shapshak P, Sinnot JT, Somboonwit C, Kuhn JH, editors. Global virology IIdentifying and investigating viral diseases. New York: Springer International Publishing AG 2015; pp. 45 - 54.

Ramasamy, R., Surendran, S.N., Jude, P.J., Dharshini, S. and Vinobaba, M. (2015). Adaptation of mosquito vectors to salinity and its impact on mosquito-borne disease transmission in the South and Southeast Asian tropics. In: Morand M, Dujardin J-P, Lefait-Robin R, Apiwathnasorn C, editors. Socio-ecological dimensions of infectious diseases in Southeast Asia . Singapore: Springer. Pp. 107 - 22.

Ramasamy, R. and Surendran, S.N. (2016). Mosquito vectors developing in atypical anthropogenic habitats - global overview of recent observations, mechanisms and impact on disease transmission. Journal of Vector Borne Diseases 53:91 - 98.

Reisen, W.K., Siddiqui, T.F., Aslamkhan, M. and Malik, G.M. (1981).Larval interspecific associations and physico-chemical relationships of the groundwater breeding mosquitoes of Lahore. Pakistan Journal of Scientific Research 331:1 - 23.

Rejmánková, E., Grieco, J., Achee, N. and Roberts, D.R. (2013). Ecology of larval habitats. In: Manguin S, editor. Anopheles mosquitoes - New insights into malaria vectors.InTech pp. 397 - 446.

Roberts, D. (1996). Mosquitoes (Diptera: Culicidae) breeding in brackish water: female oviposition preference or larval survival? Journal of Medical Entomology 33:525 - 30.

Scott, T. W. et al. (2000). Longitudinal studies of Aedes aegypti (Diptera: Culicidae) in Thailand and Puerto Rico: blood feeding frequency. Journal of Medical Entomology 37: 89 - 101.

Sharma, S.K. and Hamzakoya, K.K. (2001). Geographical spread of Anopheles stephensi, vector of urban malaria, 
and Aedes aegypti, vector of dengue/DHF, in the Arabian Sea Islands of Lakshadweep, India. Dengue Bulletin 25: 88 - 91.

Sharma, S.N., Subbarao, S.K., Choudhury, D.S. and Pandey, K.C. (1993). Role of An. culicifacies and An. stephensi in malaria transmission in urban Delhi. Indian Journal of Malariology 30: 155 - 68.

Sinka, M.E., Bangs, M.J., Manguin, S. et al. (2012).A global map of dominant malaria vectors. Parasites and Vectors 5: 69.

Sirimanne, C.H.L. (1952). Geology for water supply. Presidential address. Sec. D. CAAS: 87-118.

Singh, O.P., Dykes, L., Sharma, G. and Das, M.K.(2015). L1014F-kdr mutation in Indian Anopheles subpictus (Diptera: Culicidae) arising from two alternative transversions in the voltage-gated sodium channel and a single PIRA-PCR for their detection. Journal of Medical Entomology 52: 24 - 27.

Sumodan, P.K. (2012). Species diversity of mosquito breeding in rubber plantations of Kerala, India. Journal of the American Mosquito Control Association 28(2): $114-5$.

Sumodan, P.K., Vargas, R.M., Pothikasikorn, J., Sumanrote, A., Lefait-Robin, R. and Dujardin J.P. (2015). Rubber plantations as a mosquito box amplification in South and Southeast Asia. In: Morand M, Dujardin J-P, Lefait-Robin R, Apiwathnasorn C, editors. Socioecological dimensions of infectious diseases in Asia. Singapore:Springer, pp. 155 - 67.

Surendran, S.N., Abhayawardana, T.A., de Silva, B.G.D.N.K., Ramasamy, M.S. and Ramasamy, R. (2000). Anopheles culicifacies Y chromosome dimorphism indicates the presence of sibling species (B and E) with different malaria vector potential in Sri Lanka. Medical and Veterinary Entomology 14: 437440.

Surendran, S.N., Kannathasan, S., Kajatheepan, A. and Jude, P.J. (2007). Chikungunya-type fever outbreak: some aspects related to this new epidemic in Jaffna district, northern Sri Lanka. Tropical Medicine and Health 35:249 - 52.

Surendran, S.N. and Ramasamy, R. (2010). The Anopheles culicifacies and An. subpictus species complexes in Sri Lanka and their implications for malaria control in the island. Tropical Medicine and Health 38(1): 1-11.

Surendran, S.N., Jude, P.J., Thabothiny, V., Raveendran, S. and Ramasamy, R. (2012 ). Pre-imaginal development of Aedes aegypti in brackish and fresh water urban domestic wells in Sri Lanka. Journal of Vector Ecology 37: 471 - 3.

Surendran, S.N., Veluppillai, T., Eswaramohan, T., Sivabalakrishnan, K., Noordeen, F. and Ramasamy, R. (2018a).Salinity tolerant Aedes aegypti and Ae.albopictus- Infection with dengue virus and contribution to dengue transmission in a coastal peninsula. Journal of Vector Borne Diseases 5: 26-33.

Surendran, S.N., Sivabalakrishnan, K., Jayadas, T.T.P., Santhirasegaram, S., Laheetharan, A., Senthilnanthanan, M. and Ramasamy, R. (2018b). Adaptation of Aedes aegypti to salinity: Characterized by larger anal papillae in larvae. Journal of Vector Borne Diseases 55: 235-
238.

Surendran, S.N., Sivabalakrishnan, K., Gajapathy, K. Arthiyan, S., Jayadas, T.T.P., Karvannan, K., Raveendran, S., Karunaratne, S.H.P.P. and Ramasamy, R. (2018c). Genotype and biotype of invasive Anopheles stephensi in Mannar Island of Sri Lanka. Parasites and Vectors 11: 3 .

Surendran, S.N., Sivabalakrishnan, K., Sivasingham, A., Jayadas, T.T.P., Karvannan, K., Santhirasegaram, S., Gajapathy, K., Senthilnanthanan, M., Karunaratne, S. and Ramasamy, R., (2019a). Anthropogenic factors driving recent range expansion of the malaria vector Anopheles stephensi. Frontiers in Public Health 7: 53.

Surendran, S.N, Jayadas, T.T.P, Sivabalakrishnan, K., Santhirasegaram, S., Karvannan, K., Weerarathne, T., Parakrama Karunaratne, S. and Ramasamy, R. (2019b). Development of the major arboviral vector Aedes aegypti in urban drain-water and associated pyrethroid insecticide resistance is a potential global health challenge. Parasites and Vectors 12: 1.

Surendran, S.N., Jayadas, T.T.P., Tharsan, A. Thiruchenthooran, V., Santhirasegaram, S., Sivabalakrishnan, K., Raveendran, S.and Ramasamy, R. (2020). Anopheline bionomics, insecticide resistance and transnational dispersion in the context of controlling a possible recurrence of malaria transmission in Jaffna city in northern Sri Lanka. Parasites and Vectors $\mathbf{1 3}$ $: 156$.

Thomas, S, Ravishankaran, S, Justin, J,A, Asokan, A, Mathai, M,T, Valecha, N, et al. (2016). . Overhead tank is the potential breeding habitat of Anopheles stephensi in an urban transmission setting of Chennai, India. Malaria Journal 15:274.

UNEP. (2007). United Nations Environment Programme - Global Programme of Action for the Protection of the Marine Environment from Land-based Activities: Physical alteration and destruction of habitats. 2007, UNEP, Nairobi, Kenya, http://gpa.unep.org/content. html?id=199\&ln=6 (Accessed on 15 June 2010).

UNIPCC. (2007). United Nations Intergovernmental Panel on Climate Change: Fourth Assessment Report, Geneva.

Vithanage, M., Mikunthan, T., Pathmarajah, S., Arasalingam, S. and Manthrithilake, H. (2014). Assessment of nitrate- $\mathrm{N}$ contamination in the Chunnakam aquifer system, Jaffna Peninsula, Sri Lanka. Springerplus 3: 271.

Vittor, A.Y., Pan, W., Gilman, R.H., Tielsch, J., Glass, G., Shields, T., et al. (2009). Linking deforestation to malaria in the Amazon: Characterization of the breeding habitat of the principal malaria vector, Anopheles darlingi. American Journal of Tropical Medicine and Hygiene 81(1): 5 - 12.

Vora, N. (2008). Impact of anthropogenic environmental alterations on vector-borne diseases. The Medscape Journal of Medicine 10: 238.

WHO. (2007). Anopheline Species Complexes in South and South-East Asia. New Delhi: SEARO Technical Publication No. 57; pp. 79 - 83.

WHO. (2012). Global plan for insecticide resistance 
management in malaria vectors. Geneva: Available from http://www.who.int/malaria/publications/atoz/ gpirm/en/ (Accessed on 14 May, 2020).

WHO. (2015a). Malaria: Fact sheet. Geneva: Available from: http://www.who.int/mediacentre/factsheets/ fs094/en (Accessed on 30 July, 2015).

WHO. (2015b). Dengue and severe dengue: Fact sheet. Geneva: Available from: http:/www.who.int/ mediacentre/factsheets/fs117/en (Accessed on 30 July, 2015).

WHO. (2017). Dengue fever- Sri Lanka.https://www. who.int/csr/don/19-july-2017-dengue-sri-lanka/en/ (Accessed on 31 May 2020).

WHO. (2019). World Malaria Report. World Health Organization, Geneva.

WHO. (2020a).Lymphatic filariasis. Available from https:// www.who.int/news-room/fact-sheets/detail/lymphaticfilariasis. (Accessed on 23 May 2020).

WHO. (2020b). Dengue and Severe Dengue. Available from https://www.who.int/news-room/fact-sheets/ detail/dengue-and-severe-dengue (Accessed on 16 May 2020).

WHO. (2020c). Chikungunya. Available from https://www. who.int/news-room/fact-sheets/detail/chikungunya (Accessed on 16 May 2020)

WHO. (2020d). Zika Epidemiology Update. Available from https://www.who.int/emergencies/diseases/zika/ epidemiology-update/en (Accessed on 16 May 2020).

WHO. (2020e). Yellow Fever.Available from https://www. who.int/en/news-room/fact-sheets/detail/yellow-feve (Accessed on 16 May 2020).

Wijesundere, D.A. and Ramasamy R. (2017). Analysis of historical trends and recent elimination of malaria from Sri Lanka and its applicability for malaria control in other countries. Frontiers in Public Health 5: 212.

Yee, D. A., Himel, E., Reiskind, M.H.andVamosi, S.M. (2014). Implications of saline concentrations for the performance and competitive interactions of the mosquito Aedes aegypti (Stegomyiaaegypti) and Aedes albopictus (Stegomyiaalbopictus). Medical and Veterinary Entomology 28(1): 60 - 9. 